\title{
African librarianship rising!
}

\author{
Archie L Dick \\ University of Pretoria
}

\begin{abstract}
The two African Library Summits are reviewed. Sources for the review are analyses of plenary presentations and discussions, formal feedback from the drill-down session coordinators, and personal observation.

Keywords

African Library Summits, African librarianship, leadership, innovation.

Corresponding author

Archie L Dick, Professor, Department of Information Science, University of Pretoria, Lynnwood Road, Pretoria, Republic of South Africa, 0002.

archie.dick@up.ac.za
\end{abstract}

The first African Library Summit was held in May 2011, and the second in July 2013, in South Africa. The summits targeted African library and information service (LIS) policy-makers, LIS leaders and senior management from LIS subsectors, senior LIS educators, and senior LIS researchers. The University of South Africa (Unisa) Library, where the IFLA Africa Section is located, hosted both summits.

At the opening ceremonies, librarians, brandishing their national flags, entered the main venue, forming colourful march-pasts to the accompaniment of rhythmic percussion. The flags were on display for the duration of the proceedings. The summits were action-oriented, and by 2013 the first summit 
had fulfilled several of its expectations. Some of these can be mapped directly from expectation to implementation, in the following table:

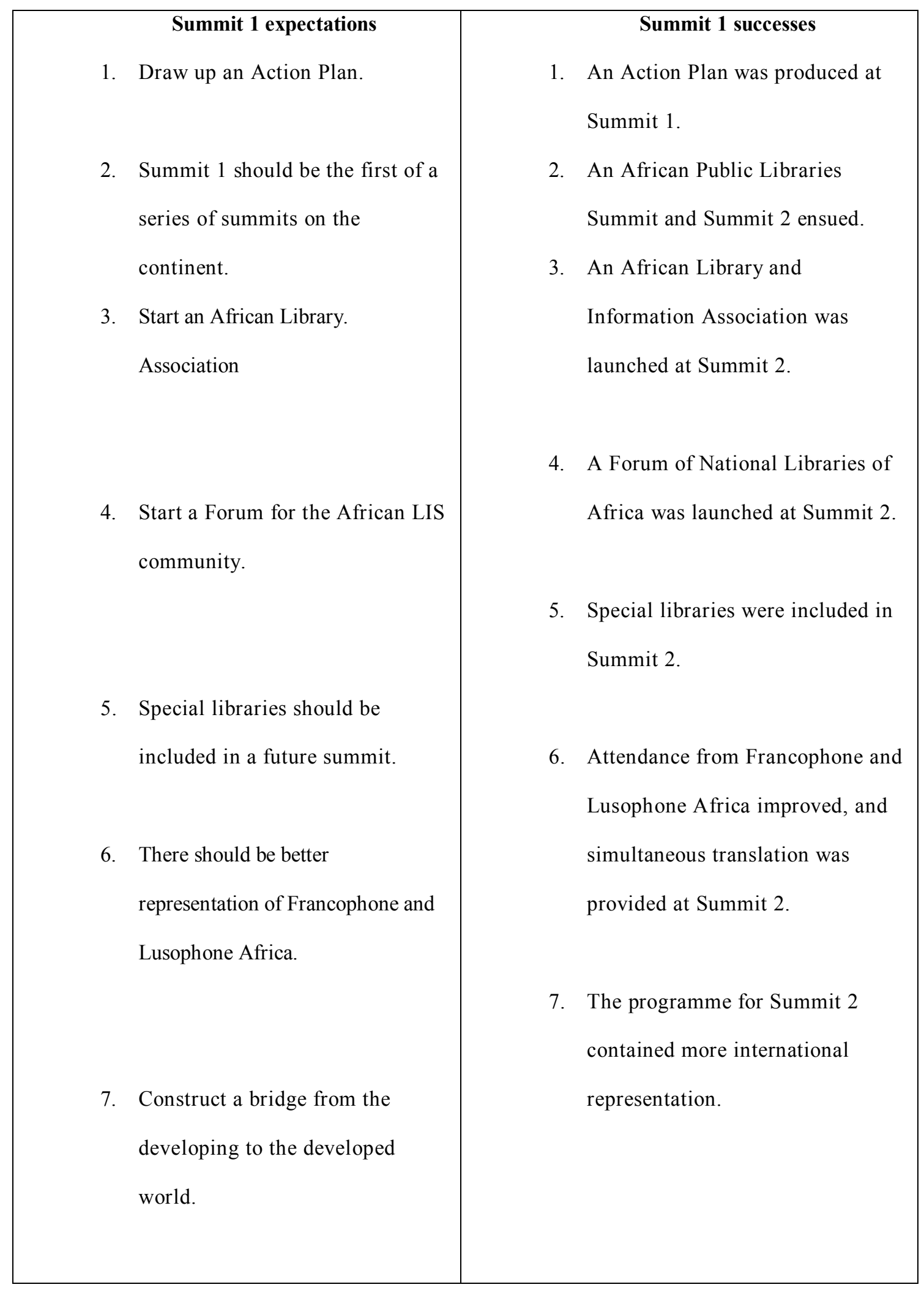


Discussions at Summit 1 were exploratory and visionary, but they were also solidly focused on the African continent. The organizers of Summit 2 changed perspective by locating African librarianship in the global context, and asking delegates to look not only to the horizon but also to what lies beyond. Leadership and innovation were the central themes of Summit 2, specifically asking how leadership should change to meet the future, and how innovation could be sustained in LIS in Africa.

Summit 1 organizers had envisioned a Promised Land of African librarianship, and imagined its contours, climate, cultures and inhabitants. They knew, however, that in all likelihood it would be occupied and managed by the next generation of librarians. For these reasons, the organizers of Summit 2 directed the speakers' thoughts to emerging leaders, and structured the programme according to leading change and sustaining innovation in this imagined library land.

This gave rise to rich discussions on the key qualities of leadership, the IFLA and other leadership initiatives in which emerging African leaders are involved, and participation by the rising generation. The presentations, networking and interventions produced some of the highlights of Summit 2, such as an inspiring talk during a lunch-break by the highly-respected Kingo Mchombu to a group of young librarians about self-discipline and public service.

Discussions on innovation at Summit 1 centred on the urgency of protecting indigenous knowledge and making it accessible in as many languages as possible. At Summit 2, the innovation focus widened to include discussions about the digital preservation of other cultures of scholarship. Some Malian manuscript copyists, for example, do not view texts as fixed and actually 
interpolate or update manuscripts as they transcribe them. For them, preservation is thus not about straightforward replication alone.

Innovation should also mean modernizing instead of Africanizing. This would lift debates above Africanist, Afrocentric and other essentialist and divisive motives. It would expect us simply to do new things well, as we would naturally do as Africans when relating to each other and our work. Work of this sort would be, for example, blending oral, literate and digital traditions.

At Summit 1, the public and community library sub-sector had discussed partnerships with academic libraries, local authorities, traditional leaders and philanthropists. These librarians had also been challenged by rural community development on how to disseminate indigenous knowledge. At Summit 2, the focus turned to ethics, mentoring and gender concerns, as well as how these should challenge emerging leaders and innovation. The response by the librarians in question suggests a broader vision and outlook that tells more about their libraries in the life of the community than about the life of the community in their libraries. In this way, for example, gender rights should be about human rights, and community needs assessments should be oriented towards non-conventional methods. Public and community librarians should, in brief, re-brand themselves.

Special librarians, conspicuous by their absence from Summit 1, joined academic and research librarians at Summit 2 and called for academic librarians to be more firmly connected with the wider academic community. This was, in fact, already taking place in publishing initiatives, as well as in matters pertaining to intellectual property rights and plagiarism. By becoming more 
scholarly themselves, academic, research, and special librarians would join their institutions in leading innovation and change.

At Summit 1, the school library sub-sector had challenged itself to produce evidence of their impact on school outcomes, and to target school principals and teachers' conferences as people and places to lobby. Aware of financial obstacles, they had discussed the possibilities of cheaper library programmes by following flexible, dual-use and other collaborative strategies. They had also called for school library policy to add information literacy education to the more technical norms and standards.

The mood at Summit 2 was very determined when it came to the ethics of denying children access to proper school libraries, and about corrupt procurement practices. Of special concern was the 'girl learner' drop-out rate at secondary schools, and a possible solution, that of attracting vulnerable learners to assist in the school library was recommended. Recognizing the essential role of school libraries in twenty-first century education in Africa, school librarians recommended building teams across all the library and information services sub-sectors to convince funders and policy makers to develop school libraries.

One of the remarkable successes of Summit 2 was the increased attendance by colleagues from Francophone and Lusophone African countries, as well as their stronger involvement in the programme by means of simultaneous translation. At Summit 1 , they had discussed the post-colonial legacy of absent library infrastructure, national policies and professional networks, and they had called for better training and more LIS schools. The recommendations at Summit 2 were positive and sharply-focused. 
These delegates suggested that performance indicators would ensure quality in the culture of service delivery, pointing out that a customer charter would promote equality in access to information. However, this kind of service would emerge only if political influence was eliminated from recruitment and promotion procedures, and equal opportunities for competent and experienced women could be guaranteed. A stronger Francophone and Lusophone contingent enlarged the African footprint of Summit 2.

Invoking the theme for Summit 2, 'The Horizon and Beyond', in her opening address, Jennefer Nicholson, the IFLA Secretary General, had challenged delegates to see what lies beyond the horizon. She also explained how the magazine the Economist had, with its front covers, shifted its view from 'Africa the hopeless continent' to 'Africa rising' in just over a decade. The response to this challenge is that Africa is rising, and African librarianship is rising too! 